\title{
ANÁLISIS COMPARATIVO DE LOS PATRONES DE MODIFICACIONES ÓSEAS DE DOS CARNÍVOROS SUDAMERICANOS: EL GATO MONTÉS (LEOPARDUS GEOFFROYI) Y EL ZORRO PAMPEANO (LYCALOPEX GYMNOCERCUS). APORTES PARA LA IDENTIFICACIÓN DE LA ACCIÓN DE PEQUEÑOS CARNÍVOROS EN EL REGISTRO ARQUEOLÓGICO
}

\author{
DANIEL J. RAFUSE*, MARIELA E. GONZÁLEZ*, CRISTIAN A. KAUFMANN*, \\ MARÍA C. ÁLVAREZ", MARÍA A. GUTIÉRREZ" \& AGUSTINA MASSIGOGE
}

\begin{abstract}
RESUMEN
El objetivo de este trabajo es caracterizar y comparar los patrones de modificaciones óseas producidos por dos carnívoros autóctonos de Sudamérica, el zorro pampeano y el gato montés, sobre partes esqueletarias de pequeños vertebrados. Para esto se realizó una experiencia en un parque zoológico local, ofreciendo 10 conejos en forma controlada, a cada uno de los predadores mencionados. En esta oportunidad se presentan los resultados de los restos no ingeridos, para los cuales se analizó la representación anatómica y los patrones de fractura. Los resultados indican que tanto el gato montés como el zorro pampeano generan una destrucción ósea significativa en los restos de conejo, lo cual impacta directamente en la representación de los individuos. Los elementos con mayor supervivencia fueron los huesos largos, la pelvis, el cráneo y la mandíbula. Por otra parte, la densidad ósea resultó ser uno de los factores que condicionó la destrucción diferencial de los elementos. Si bien nuestros resultados no permiten diferenciar las modificaciones generadas por estas dos especies de carnivoros, los patrones observados aportan nuevos datos que ayudan a distinguir estos conjuntos de aquellos originados por otros predadores como por ejemplo, aves rapaces diurnas y nocturnas.
\end{abstract}

PALABRAS CLAVE: tafonomía experimental, gato montés, zorro pampeano, pequeños vertebrados, modificaciones óseas.

COMPARATIVE ANALYSIS OF BONE MODIFICATION PATTERNS PRODUCED BY TWO SOUTH AMERICAN CARNIVORES: THE GEOFFROY'S CAT (LEOPARDUS GEOFFROYI) AND THE PAMPAS FOX (LYCALOPEX GYMNOCERCUS). CONTRIBUTIONS TO THE IDENTIFICATION OF THE ACTION OF SMALL CARNIVORES IN THE ARCHAEOLOGICAL RECORD

\footnotetext{
ABSTRACT

The objective of this paper is to characterize and compare the bone modification patterns on small vertebrate skeletal parts produced by two native South American carnivores, the Pampas fox and the Geoffroy's cat. To accomplish this, an experimental study was conducted at a local zoo, where 
each predator was routinely offered 10 domestic rabbits. The results of the non-ingested remains are presented, including the anatomical representation and the fracture patterns. The results indicate that both the Geoffroy's cat and the Pampas fox generate significant bone destruction on rabbit remains, which impacts directly on the representation of individuals. Elements with greater survival rates include the long bones, innominate, cranium and mandible. In addition, bone density was found to be a factor which determines the differential destruction of elements. While our results cannot distinguish the patterns generated by these two species of carnivorous, observed modifications provide new data to help distinguish these assemblages from those caused by other predators such as diurnal and nocturnal birds.

KEY WORDS: experimental taphonomy, Geoffroy's cat, Pampas fox, small sized vertebrates, bone modifications.

\section{INTRODUCCIÓN}

Los carnívoros destruyen las carcasas de sus presas con variada intensidad. En este proceso entran en juego aspectos físicos, como la talla del predador y la presa y la fuerza mandibular, así como ecológicos, como la organización social del carnívoro, su ubicación en la escala trófica y el nivel de competencia interespecífica, entre otros. Estas condiciones introducen una gran variabilidad en la forma de consumo. En algunas oportunidades, la presa es consumida completa y sus restos óseos son depositados en forma de excrementos. En otras ocasiones, el predador se concentra en porciones que poseen mayor rendimiento nutricional, $e$ incluso en algunos casos sólo se alimenta de la grasa y la carne, dejando prácticamente intacto el sistema óseo de la presa (Haynes 1980; Binford 1981; Cochard 2008).

Los conjuntos zooarqueológicos de distintas áreas geográficas frecuentemente registran huesos con modificaciones vinculadas a la acción humana (i.e., huellas de procesamiento de carcasas) y de carnivoros (i.e., perforaciones, hoyuelos, arrastres, cilindros óseos), entre otras. Los estudios de dichas modificaciones permiten indagar acerca de la interacción de los humanos y los carnívoros en el pasado, así como sobre los procesos de formación del registro arqueofaunístico. Una forma de abordar la interacción de estos dos agentes es a través de estudios actualísticos, tanto experimentales como naturalistas (Marean 1995). Los abordajes experimentales que identifican los patrones de modificaciones óseas de carnívoros reflejados en la representación de partes esqueletarias, características de las marcas (tipo, tamaño, frecuencia y localización) y fracturas, contribuyen a evaluar la relación entre los seres humanos y los predadores, el tamaño y taxón de los carnívoros involucrados (i.e., cánidos vs. félidos), el momento de acceso a las carcasas y el recurso de su preferencia (tipos de presa, recursos nutricionales obtenidos). Todos ellos son aspectos importantes para entender la relación entre los seres humanos y otros predadores, caracterizar las estrategias de subsistencia llevadas a cabo por los grupos humanos en el pasado y brindar confiabilidad a las interpretaciones paleoambientales. Si bien este tipo de estudios ha prosperado notablemente en el mundo en los últimos años, en Sudamérica se ha establecido sólo recientemente (Elkin \& Mondini 2001; Gómez 2007; Montalvo et al. 2007, 2008, 2011; Mondini 2011; Mondini \& Muñoz 2011; entre otros).

La acción de carnívoros sobre presas de pequeño tamaño resulta particularmente relevante para las investigaciones arqueológicas. La importancia de los vertebrados pequeños (e.g., vizcacha, Lagostomus maximus; coipo, Myocastor coypus; cuis, Cavia aperea; degú, Octodon degus; armadillos) en la dieta de los cazadoresrecolectores del extremo sur sudamericano ha sido claramente demostrada en las últimas décadas (Simonetti y Cornejo 1991; Quintana et al. 2002; Santiago 2004; Labarca 2005; Medina et al. 2011; Escosteguy et al. 2012; Stoessel 2012; Tivoli 2012; entre otros). Existe una superposición en el consumo de estos pequeños vertebrados por parte de los humanos y los carnívoros pequeños y medianos (zorros, Lycalopex sp.; zorrino, Conepatus chinga; gato montés) (Manfredi et al. 2004; Lucherini y Luengos Vidal 2008). Este 
dato resulta relevante para las investigaciones zooarqueológicas ya que, a partir de diferentes estudios tafonómicos, se ha demostrado que los carnivoros pueden incorporar huesos de fauna menor al registro arqueológico (e.g., fecas y restos de presas no ingeridas). En consecuencia, se torna fundamental distinguir el agente acumulador de los conjuntos faunísticos conformados por vertebrados pequeños, para brindar mayor confiabilidad a las interpretaciones. Esta información es necesaria para la discusión de distintos temas referidos a la subsistencia (e.g., diversificación de la dieta), el rol de algunos mamíferos pequeños en la dimensión simbólica o la presencia de perros en las sociedades cazadoras-recolectoras, entre otros tópicos en los cuales se han centrado las discusiones recientes de la arqueología de Sudamérica meridional (Quintana et al. 2002; Acosta y Pafundi 2005; Labarca 2005; Bonomo 2006; Prates et al. 2010; Tivoli 2012; entre otros).

El objetivo de este trabajo experimental es caracterizar y comparar los patrones de modificación ósea producidos por dos carnivoros autóctonos de Sudamérica, el zorro pampeano (Lycalopex gymnocercus) y el gato montés (Leopardus geoffroyi), sobre partes esqueletarias de pequeños vertebrados. Estas dos especies son predadores de distintos vertebrados de tamaño pequeño, cuyos restos son comúnmente hallados en los sitios arqueológicos. Este artículo se centra en el análisis de los restos óseos no ingeridos, a través de la descripción de los patrones de modificación generados por los carnívoros en términos de representación anatómica y fracturas. Además, se intentará evaluar si existen diferencias en dichos patrones, que permitan eventualmente reconocer al grupo taxonómico que contribuyó a la formación de un conjunto dado. La importancia de poder identificar conjuntos generados por cánidos y félidos radica en, al menos, dos aspectos: la integridad de los registros faunísticos y sus consecuentes interpretaciones arqueológicas y la interacción entre grupos humanos y los predadores. Las características eto-ecológicas de ambas familias muestran que los cánidos, en términos generales, presentan un mayor componente carroñero que los félidos (Novaro et al. 2000; Castillo et al. 2011). Considerando este comportamiento, distinguir el agente responsable de las modificaciones permite discutir la posibilidad de que la presa haya ingresado al registro por predación natural, carroñada, o haya sido compartida con los humanos.

Los huesos de pequeños cánidos y félidos son comúnmente hallados en sitios arqueológicos de Pampa y Patagonia (Miotti y Salemme 1999; Mazzanti y Quintana 2001; Martínez y Gutiérrez 2004; Álvarez 2009; Zubimendi et al. 2010; Bastourre y Salazar Siciliano 2012). Argentina posee una notable diversidad de felinos y cánidos del Neotrópico. Los félidos pequeños (entre 2 y 9 $\mathrm{kg}$ ) están representados actualmente en nuestro país por siete especies: margay (Leopardus wiedii); tigrillo (Leopardus tigrina); gato andino (Leopardus jacobita); yaguarundí (Puma yaguarondi); gato de los pajonales (Leopardus colocolo); gato montés (Leopardus geoffroyi) y huiña (Oncifelis guigna) (Lucherini et al. 2004). Por su parte, los cánidos de pequeño porte (entre 3 y $23 \mathrm{~kg}$ ) están representados en Argentina por cinco especies: zorro de monte (Cerdocyon thous); aguará guazú (Chrysocyon brachyurus); zorro colorado (Lycalopex culpaeus); zorro pampeano (Lycalopex gymnocercus) y zorro vinagre (Speothos venaticus) (Redford y Eisenberg 1992; Prevosti et al. 2013).

La distribución del gato montés incluye gran parte de Bolivia, el sur de Brasil, Argentina y Chile (Johnson y Franklin 1991; Lucherini et al. 2006). Este carnivoro es principalmente nocturno y habita tanto en ambientes secos como semiáridos. Es un predador oportunista y su dieta actual consiste en lagomorfos, pequeños roedores y aves (Ximénez 1975; Manfredi et al. 2004, 2011; Perovic y Pereira 2006). El peso promedio del macho adulto es de alrededor de $4,9 \mathrm{~kg}$, en tanto que las hembras pesan cerca de 4,2 kg (Cabrera y Yepes 1960; Johnson y Franklin 1991; Oliveira 1994; Lucherini et al. 2006). La distribución del zorro pampeano es más restringida que la del gato montés. Ésta incluye Bolivia, el oeste de Paraguay, el sur de Brasil y las pampas de Argentina. Este animal es oportunista y generalista y las presas autóctonas más abundantes en su dieta son la vizcacha y distintas especies de ratones, aunque también consume aves, vegetales, frutas e insectos. Los machos adultos pesan alrededor de $5,4 \mathrm{~kg}$, mientras que las hembras pesan cerca de $4,4 \mathrm{~kg}$. Ambos carnívoros cazan principalmente de noche, aunque algunos cánidos tienen actividades diurnas 
ocasionales (Nowak 1991).

El comportamiento de alimentación de ambos predadores difiere principalmente en que los félidos son hipercarnivoros (Christiansen y Wroe 2007: 356), en tanto que los cánidos pequeños, como los zorros, son omnívoros. Estas características se observan también en la morfología craneal, dado que los félidos tienen un mayor tamaño de área de corte en los molares carniceros y una menor área de trituración en los molares, en tanto que los cánidos poseen una mayor capacidad trituradora y un patrón dental generalizado (Zapata et al. 2008).

\section{MATERIALES Y MÉTODOS}

Los experimentos desarrollados en este trabajo fueron llevados a cabo con dos ejemplares de gato montés y un zorro pampeano en el Parque Zoológico La Máxima, localizado en la ciudad de Olavarría (provincia de Buenos Aires, Argentina). A cada especie se le ofreció un total de 10 conejos (Oryctolagus cuniculus) completos, los cuales pesaban en promedio unos $3 \mathrm{~kg}$ y correspondían a las categorías subadulto y adulto. En cada evento de alimentación se colocó una presa completa dentro del hábitat de cada carnívoro, la cual fue segmentada en mitad anterior y posterior por protocolo del zoológico. Luego de tres días, durante los cuales no se brindó ningún otro alimento a los carnívoros, se recolectaron los restos óseos no ingeridos y las fecas. La elección del conejo doméstico en este experimento se basó en que su tamaño y su estructura ósea son similares a la de los pequeños mamíferos nativos que habitaron la región pampeana durante tiempos prehistóricos, incluyendo la vizcacha (ca. $4 \mathrm{~kg}$ ), el coipo (ca. $7,5 \mathrm{~kg}$ ) y la liebre patagónica o mara (Dolichotis patagonum, ca. $8 \mathrm{~kg}$ ). Aunque hubiera sido preferible experimentar con presas nativas $\mathrm{u}$ otros pequeños mamíferos sudamericanos, los mismos no están localmente disponibles para experimentaciones sistemáticas o se trata de especies protegidas (i.e., mara).

En este trabajo se presentan los resultados del análisis de la representación anatómica y de los patrones de fractura en las muestras de los restos óseos de conejo no ingeridos generados por ambos carnívoros. En consecuencia, los resultados no reflejarán el total de los restos que pueden resultar de la actividad de estos predadores. En relación con las medidas de abundancia de partes esqueletarias, se calculó el número mínimo de elementos (NME) y la abundancia relativa (Ri) (Andrews 1990). Para esto se consideró la relación proporcional entre el número de veces que un elemento determinado estaba representado en la muestra estudiada y el número esperado de este elemento $(\mathrm{Ei})$ en relación al número mínimo de individuos (NMI): $\mathrm{Ri}=\left(\mathrm{N}_{\mathrm{i}} /\right.$ NMIxE) (Andrews 1990:45).

El número mínimo de individuos (NMI) fue calculado a partir de la suma de los elementos esqueletarios más frecuentes, considerando su lateralidad (Andrews 1990). Con el objetivo de evaluar en qué medida el patrón de destrucción generado por ambos carnívoros estuvo mediado por la densidad mineral ósea (DMO), se comparó la frecuencia relativa de partes $(\mathrm{Ri})$ con un índice elaborado por Pavao y Stahl (1999) para conejo doméstico.

La representación de determinados grupos de elementos fue establecida a partir de la aplicación de los siguientes índices:

A) Proporción de elementos craneales en relación a los elementos postcraneales, a partir del índice PCRT/CR: [(fémur + húmero)/(mandíbula + maxila)] x 100 (Andrews 1990).

B) Proporción de elementos distales en relación a los elementos proximales, por medio del índice C/E: [(tibia + ulna)/(fémur + húmero)] $\mathrm{x}$ 100 (Andrews 1990).

C) Proporción de elementos de la extremidad anterior y posterior, considerando el índice AN/PO: [(húmero + radio + ulna + metacarpo)/(fémur + tibia + metatarso)] x 100 (Lloveras et al. 2008).

D) Relación entre el esqueleto postcraneal axial y el apendicular, utilizando el índice AX/AP: [(Vértebras + costillas) x 10/ (húmero + ulna + radio + fémur + tibia) x 66] x 100 (Álvarez et al. 2012).

Conjuntamente, se utilizó un programa informático de SIG (Sistema de Información Geográfica) (ArcView 3.2; ERSI Inc.) para estimar el NME de los huesos largos y la cintura pélvica y la escapular. Cada fragmento identificado anatómicamente fue dibujado sobre una imagen del elemento en el programa. Este método permite 
identificar si dos fragmentos correspondientes a un mismo elemento se superponen, con el fin de estimar el NME (Marean et al. 2001). El mismo permite ajustar la cuantificación de los especímenes pertenecientes a la diáfisis y expresar de forma visual los patrones de supervivencia diferencial a nivel intra-elemento. En el futuro, con el desarrollo de nuevos experimentos, estas imágenes servirán para estimar con rapidez y eficacia los valores de NME sin la necesidad de revisar manualmente la colección.

Se asignaron categorías de integridad para cada espécimen siguiendo la propuesta de Lloveras et al. (2009). La completitud porcentual $(\mathrm{C} \%)$ de cada elemento fue calculada a través de la proporción del NISP y número de elementos completos. Durante la limpieza de los restos se observaron varios casos en que los dientes se desprendieron de sus alveolos por la remoción del tejido blando; por este motivo, se decidió no utilizar medidas de completitud para el material dentario, así como tampoco índices que evalúan y/o consideran la pérdida de molares e incisivos (i.e., Andrews 1990; Fernández-Jalvo y Andrews 1992).

\section{RESULTADOS}

En el experimento llevado a cabo con gato montés se recuperó un total de 792 especímenes, de los cuales el $55,2 \%$ pudo ser identificado anatómicamente y se calculó un NMI de ocho a partir de la pelvis. En el caso del zorro pampeano se recobró un total de 639 especímenes óseos, de los cuales el 85,6\% fue determinado anatómicamente y se estableció un NMI de seis, obtenido a través de la maxila y la tibia. El promedio de abundancia relativa generado por gato montés fue de $40,2 \%$, en tanto aquel producido por el zorro fue del 50,2\%, lo cual indica que ambas especies ocasionaron una significativa pérdida ósea en sus presas (Tabla 1).

La frecuencia relativa de partes esqueletarias generada por ambos carnívoros fue, en general, similar. En este sentido, en las dos muestras se observó una ausencia de las costillas y una baja supervivencia de las vértebras y las escápulas, en tanto que los elementos más abundantes fueron los huesos largos, la pelvis, el cráneo y la mandíbula. Por otro lado, algunos elementos mostraron diferencias
Tabla 1. Especímenes óseos no ingeridos recuperados para gato montés y zorro pampeano.

\begin{tabular}{|c|c|c|}
\hline & Gato montés & Zorro pampeano \\
\hline $\begin{array}{c}\text { Número de } \\
\text { especímenes óseos }\end{array}$ & 792 & 639 \\
\hline $\begin{array}{c}\text { Identificados } \\
\text { anatómicamente }\end{array}$ & 438 & 547 \\
\hline $\begin{array}{c}\text { Número mínimo de } \\
\text { individuos }\end{array}$ & 8 & 6 \\
\hline $\begin{array}{c}\text { Abundancia relativa } \\
\text { promedio }\end{array}$ & $40,2 \%$ & $50,2 \%$ \\
\hline
\end{tabular}

en la supervivencia, como es el caso de los huesos del tarso/carpo y las falanges, que presentan valores mucho menores de Ri en la muestra de gato montés que en la de zorro pampeano (Tabla 2, Figura 1). La correlación entre el Ri y la DMO resultó positiva y significativa para el conjunto producido por el gato $\left(r_{\mathrm{s}}=\right.$ $0,468 ; p=0,0002)$ y positiva y no significativa para la muestra originada por el zorro $\left(r_{\mathrm{s}}=0,257 ; p=0,055\right)$. Estos resultados indican que los perfiles anatómicos de los restos no ingeridos estarían mediados, en cierto grado, por esta propiedad intrínseca de los huesos.

Para ambos predadores, el índice que evalúa la relación entre los elementos apendiculares (fémur y húmero) con la mandíbula y la maxila muestra una mayor representación de elementos craneales. El índice que considera la proporción de elementos del estilopodio (húmero y fémur) en relación al cigopodio (ulna y tibia) (C/E) indica que ambos grupos de elementos están representados en proporciones similares en el gato montés. En el caso del zorro, el cigopodio está ligeramente mejor representado con respecto al estilopodio. En relación con el índice que evalúa las extremidades anteriores y posteriores, se observa una tendencia inversa: en el gato montés las extremidades posteriores están mejor representadas, en tanto que en el caso del zorro lo están las anteriores. Para ambos carnívoros, el índice que evalúa el esqueleto axial postcraneal y el apendicular (AX/AP) indica una elevada pérdida del esqueleto axial (Tabla 3).

El porcentaje de elementos completos fue considerablemente menor en la muestra del gato en relación con la del zorro, tanto si se considera el total de especímenes como sólo los determinables (Tabla 2). Asimismo, se calculó la completitud porcentual (C\%) para todos los huesos largos (excluyendo los 
Tabla 2. Medidas de abundancia relativa en las muestras de especímenes óseos no ingeridos generados por gato montés y zorro pampeano.

\begin{tabular}{|c|c|c|c|c|c|c|c|c|c|c|}
\hline Elemento & \multicolumn{5}{|c|}{ Gato montés } & \multicolumn{5}{|c|}{ Zorro pampeano } \\
\hline esqueletario & NISP & NME & $\mathrm{Ri}$ & $\mathrm{EC}$ & $\mathrm{C} \%$ & NISP & NME & $\mathrm{Ri}$ & $\mathrm{EC}$ & $\mathrm{C} \%$ \\
\hline Cráneo & 15 & 11 & 68,7 & 2 & 13,3 & 38 & 10 & 83,3 & 2 & 5,3 \\
\hline Mandíbula & 14 & 12 & 75 & 3 & 21,4 & 10 & 10 & 83,3 & 7 & 70,0 \\
\hline Molar superior* & 31 & 31 & 25,8 & - & - & 10 & 10 & 13,9 & - & - \\
\hline Molar inferior* & 23 & 23 & 28,7 & - & - & 4 & 4 & 6,6 & - & - \\
\hline Incisivo* & 14 & 14 & 29,2 & - & - & 2 & 2 & 5,5 & - & - \\
\hline Vértebra & 18 & 17 & 4,9 & 13 & 72,2 & 41 & 39 & 15,1 & 33 & 80,5 \\
\hline Costilla & 0 & 0 & 0 & 0 & 0 & 0 & 0 & 0 & & 0 \\
\hline Escápula & 4 & 4 & 25 & 0 & 0 & 1 & 1 & 8,3 & 0 & 0 \\
\hline Húmero & 5 & 5 & 31,2 & 2 & 40 & 7 & 7 & 58,3 & 3 & 42,9 \\
\hline Radio & 10 & 7 & 43,7 & 0 & 0 & 9 & 9 & 75 & 5 & 55,6 \\
\hline Ulna & 9 & 7 & 43,7 & 2 & 22,2 & 8 & 8 & 66,6 & 5 & 62,5 \\
\hline Pelvis & 17 & 13 & 81,2 & 2 & 11,8 & 8 & 8 & 66,6 & 2 & 25 \\
\hline Fémur & 20 & 14 & 87,5 & 3 & 15 & 7 & 7 & 58,3 & 4 & 57,1 \\
\hline Tibia & 16 & 12 & 75 & 2 & 12,5 & 10 & 10 & 83,3 & 4 & 40 \\
\hline Rótula & 4 & 4 & 25 & 4 & 100 & 0 & 0 & 0 & 0 & 0 \\
\hline Calcáneo & 7 & 7 & 43,7 & 7 & 100 & 9 & 9 & 75 & 9 & 100 \\
\hline Astrágalo & 6 & 6 & 37,5 & 6 & 100 & 9 & 9 & 75 & 9 & 100 \\
\hline Carpo/tarso & 65 & 65 & 33,8 & 65 & 100 & 91 & 91 & 63,2 & 91 & 100 \\
\hline Metacarpo & 8 & 8 & 10 & 8 & 100 & 40 & 40 & 66,7 & 40 & 100 \\
\hline Metatarso & 40 & 40 & 62,5 & 32 & 80 & 33 & 32 & 66,7 & 24 & 72,7 \\
\hline Falange 1-2 & 77 & 76 & 27,9 & 69 & 89,6 & 138 & 138 & 67,6 & 137 & 99,3 \\
\hline Falange 3 & 35 & 35 & 24,3 & 35 & 100 & 72 & 72 & 66,7 & 72 & 100 \\
\hline Restos indet. & 354 & - & - & - & - & 92 & - & - & - & - \\
\hline Total 1 & 438 & 411 & 884,3 & 255 & 68,92 & 547 & 516 & 1105 & 447 & 84,18 \\
\hline Total 2 & 792 & - & - & - & 35,22 & 639 & - & - & - & 69,19 \\
\hline
\end{tabular}

Referencias: NISP: número de especímenes óseos, NME: número mínimo de elementos, Ri: frecuencia relativa de partes, EC: elementos completos, C\%: completitud porcentual; *estos elementos no fueron considerados para estimar el porcentaje de completitud de los huesos que integraban la muestra. Total 1: cálculos sin considerar los restos indeterminados; Total 2: cálculos considerando los restos indeterminados.

metacarpos y metatarsos). Este resultado mostró nuevamente una menor $\mathrm{C} \%$ para el gato montés $(\mathrm{C} \%=15 \%)$ en relación al zorro pampeano $(\mathrm{C} \%=$ $51,2 \%)$.

Considerando la C\% de cada elemento para ambas muestras analizadas, se observa que todos los huesos recuperados del carpo, tarso y las falanges están completos (Tabla 2, Figura 2). Por otro lado, los metapodios y las vértebras presentan una alta C\% (entre ca. 73 y 100\%), en tanto que los huesos largos presentan menores valores (ca. 12 a 62\%). Las cinturas escapular y pélvica tienen una escasa C\%; todas las escápulas están fragmentadas, en tanto que la pelvis presenta valores menores al $25 \%$. Los 


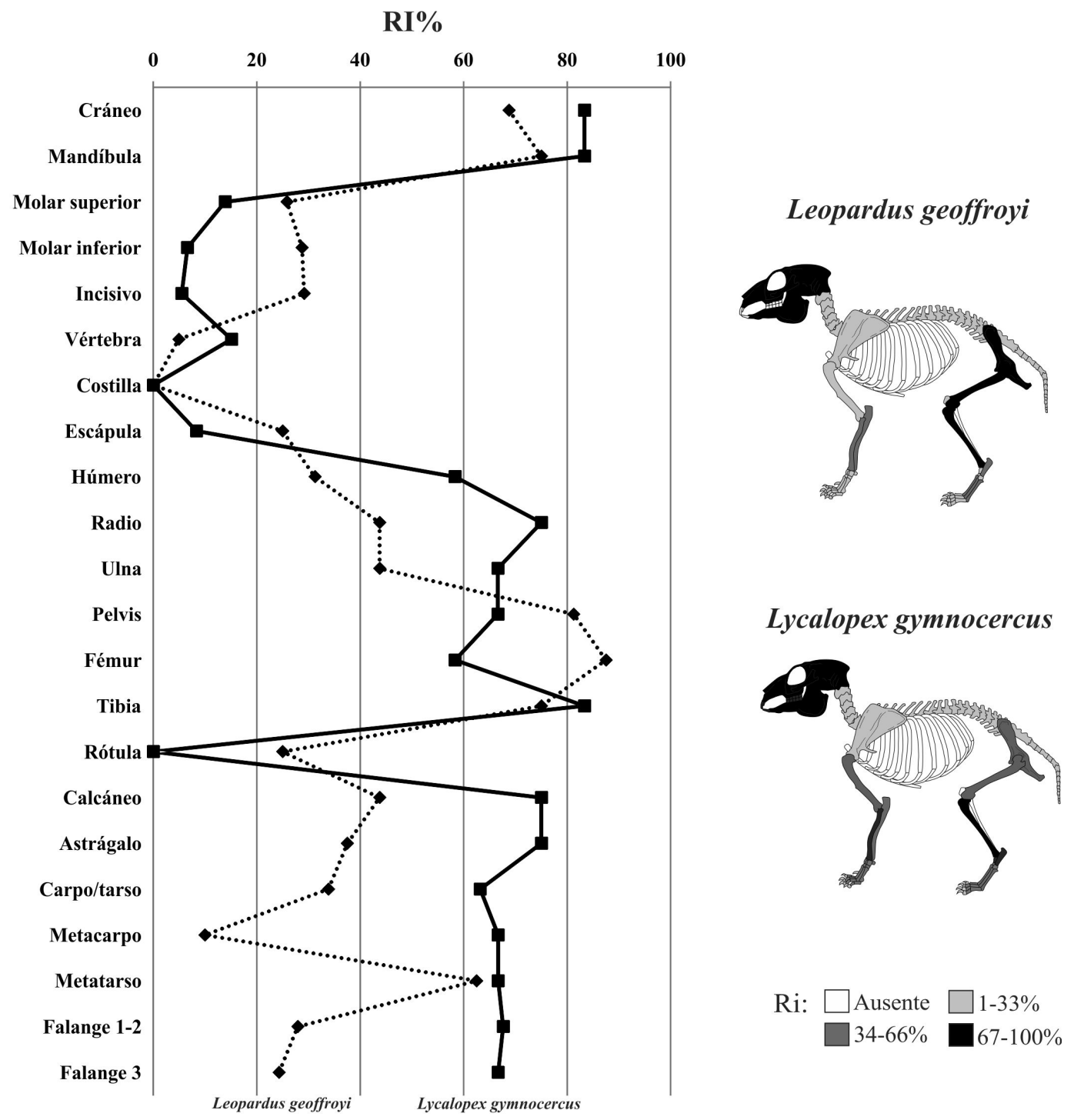

Fig.1 Representación relativa de los especímenes óseos no ingeridos de conejo generada por gato montés y zorro pampeano.

cráneos tienen valores menores al $13 \%$, mientras que los resultados de la mandíbula fueron más variables. Finalmente, no se recuperaron costillas, con lo cual no pudo calcularse su C\% (Tabla 2, Figura 2).

A partir del análisis de SIG se calculó la supervivencia diferencial a nivel intra-elemento para los huesos largos y la cintura pélvica y la escapular (Figuras 3 y 4). Como se observa en las imágenes, ambos predadores muestran tendencias similares en relación a la destrucción ósea de las distintas porciones. Sin embargo, se destacan algunas diferencias, particularmente en el fémur y la pelvis de la muestra del gato montés. En cuanto al fémur, las porciones que más sobrevivieron fueron la cabeza y la diáfisis medial, en relación con la diáfisis distal y el trocánter mayor (Figura 3). En el caso de la pelvis, la mayor supervivencia corresponde a la rama del ilion y el acetábulo, en tanto que la zona de la cresta y espina ilíaca y las tuberosidades isquiáticas presentan los menores valores. Para el zorro pampeano, el radio, la ulna y el fémur muestran una supervivencia similar de las distintas porciones. Para ambos predadores, se observa una mayor destrucción de las epífisis y metáfisis proximales tanto en la tibia como en el 
húmero, mientras que los sectores distales exhiben una mayor supervivencia. El radio y la ulna tuvieron una supervivencia variable; la carilla articular proximal de la ulna sufrió una menor destrucción que el olécranon. Con respecto a la escápula, se destaca la ausencia de la porción distal de la hoja y el acromion en todos los casos, en tanto que la mayor supervivencia se observa para el cuello y la cavidad glenoidea (Figuras 3 y 4).

\section{DISCUSIÓN Y CONCLUSIONES}

Los resultados aquí presentados indican que tanto el gato montés como el zorro pampeano generan una destrucción ósea significativa en los restos de conejo, lo cual impacta directamente en la estimación del NMI. Como fue presentado en este trabajo, de los 10 individuos ofrecidos a ambos carnívoros sólo pudieron cuantificarse ocho para el gato montés y seis para el zorro, al final del experimento. Por otro lado, los resultados de la abundancia relativa promedio, así como de los indices calculados, muestran que ambos predadores presentan patrones similares de destrucción de los
Tabla 3. Resultados de los índices que evalúan la representación anatómica para los especímenes óseos no ingeridos recuperados para gato montés y zorro pampeano.

\begin{tabular}{|c|c|c|}
\hline Índices & Gato montés & Zorro pampeano \\
\hline $\mathbf{P C R T / C R}$ & 82,6 & 70 \\
\hline $\mathbf{C} / \mathbf{E}$ & 100 & 128,6 \\
\hline $\mathbf{A N} / \mathbf{P O}$ & 30,7 & 136,6 \\
\hline $\mathbf{A X} / \mathbf{A P}$ & 5,7 & 14,4 \\
\hline
\end{tabular}

Referencias: $\mathrm{PCRT} / \mathrm{CR}=$ Proporción de elementos craneales en relación a los elementos post-craneales; $\mathrm{C} / \mathrm{E}=$ Proporción de elementos distales en relación a los elementos proximales; $\mathrm{AN} / \mathrm{PO}=$ Relación entre el esqueleto postcraneal axial y el apendicular; $\mathrm{AX} / \mathrm{AP}=$ Proporción de elementos de la extremidad anterior y posterior.

elementos esqueletarios.

Entre los elementos con mayor supervivencia se encuentran el cráneo y la mandíbula para ambas especies. Este es un aspecto positivo, ya que estas partes anatómicas son las más adecuadas para la identificación taxonómica en conjuntos arqueológicos. La pelvis y los huesos largos presentan, en general, una buena supervivencia, si

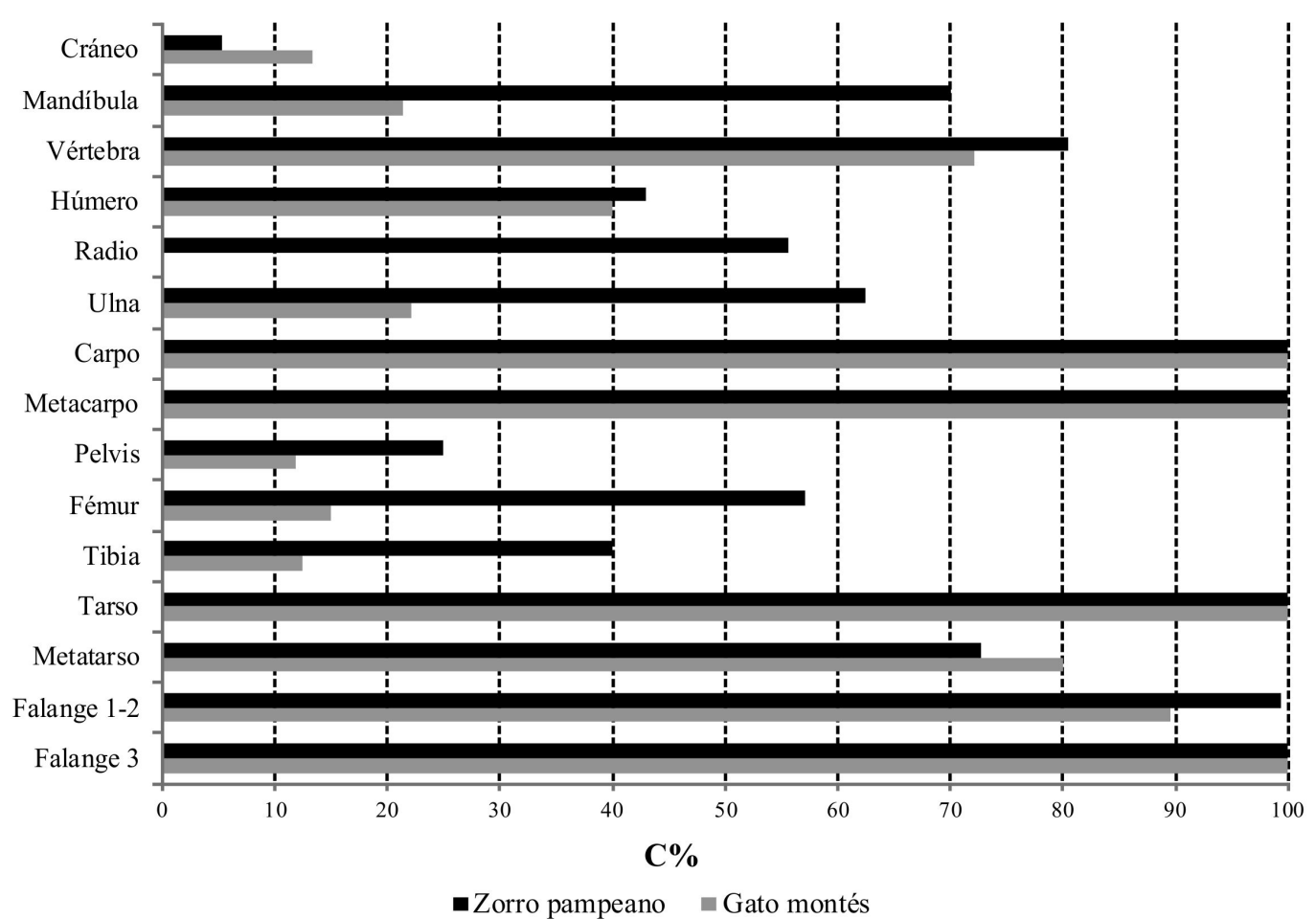

Figura 2. Porcentaje de completitud porcentual (C\%) por elemento para los especímenes óseos no ingeridos recuperados para gato montés y zorro pampeano. 


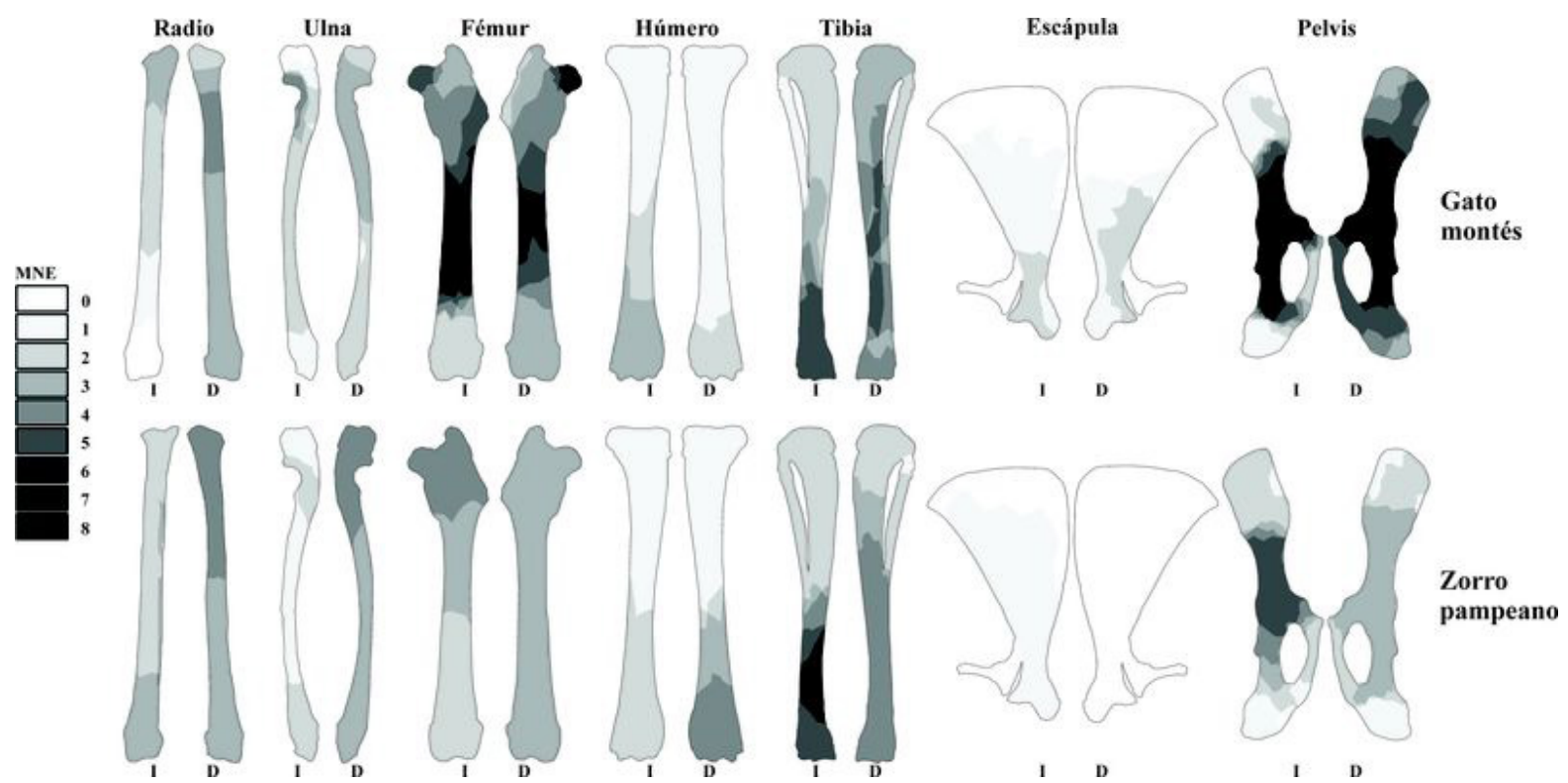

Figura 3. Supervivencia de las porciones intra-elemento obtenidas con SIG para los especímenes óseos no ingeridos recuperados para gato montés y zorro pampeano.

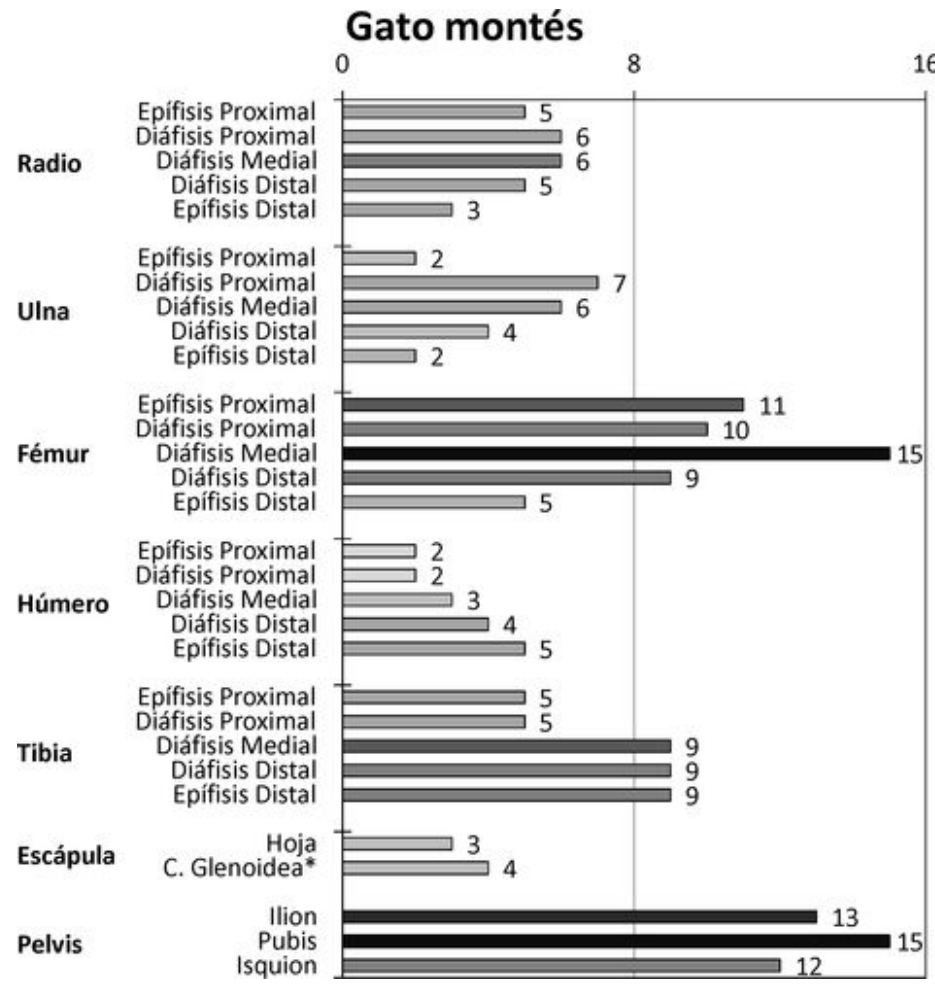

\section{Zorro pampeano}

16

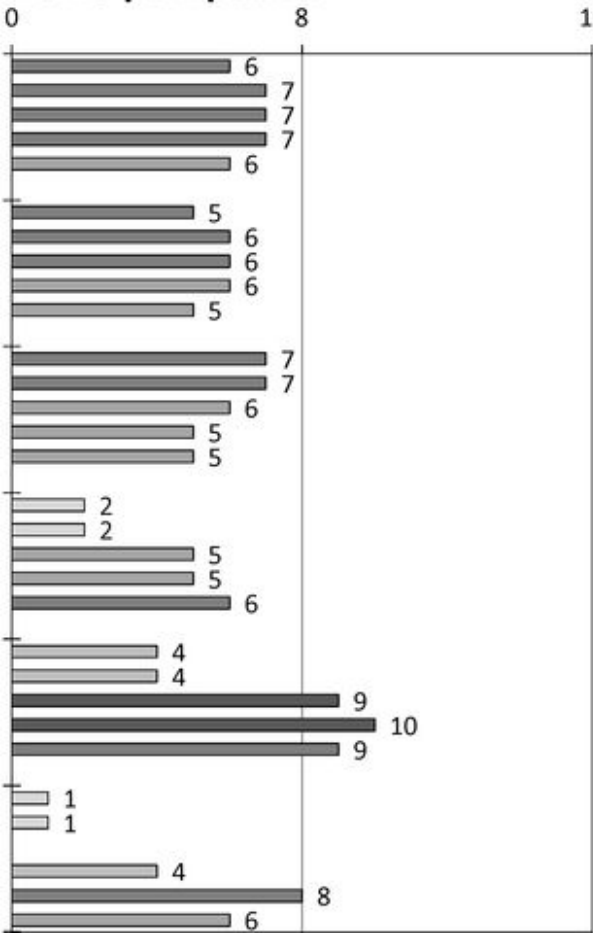

Figura 4. NME de las porciones intra-elemento obtenidas con SIG para los especímenes óseos no ingeridos recuperados para gato montés y zorro pampeano. C. gleonidea (marcado con un asterisco) refiere al sector que incluye esta porción, junto con el acromion y cuello de la escápula. 
bien la misma es más variable para estos últimos. Por su parte, algunos elementos axiales mostraron una muy baja supervivencia, como las vértebras y las costillas, estas últimas ausentes en ambas muestras. En líneas generales, se observó que los restos no ingeridos del zorro presentan una mayor supervivencia que aquellos del gato y muestran un mayor porcentaje de huesos del carpo, tarso y falanges. Por este motivo, el porcentaje de elementos identificados es mayor en la muestra del zorro.

En la muestra del gato montés hubo una correlación positiva y significativa entre la abundancia relativa de las partes esqueletarias y la densidad mineral. En el caso del conjunto generado por el zorro, la misma fue positiva y muy cercana al límite de significación. Estos datos sugieren que esta propiedad ósea es uno de los factores que condiciona la destrucción diferencial. Por otro lado, si bien la escasa representación o ausencia de algunos de los elementos con baja densidad como vértebras y costillas puede ser resultado de su destrucción, es necesario considerar que algunos huesos pequeños de las partes inferiores de las patas y de alta densidad (tarsos, carpos y falanges) pudieron ser ingeridos completos por los predadores. Por este motivo es probable que muchos de ellos sean recuperados en las fecas, tal como se observó durante el procesamiento de estas muestras, el cual aún no ha finalizado. En este sentido, los resultados de la correlación entre la densidad mineral y los patrones de partes podrían modificarse cuando se incorporen al análisis los restos ingeridos presentes en las fecas. Estos datos serán de mayor utilidad para la comparación con los conjuntos fósiles, en los cuales ambos tipos de restos se presentan agregados.

Con respecto a la completitud general, los valores obtenidos fueron similares para ambos predadores. Considerando cada uno de los elementos, la mayor completitud se registró para los metapodios y las vértebras. No obstante, dado el escaso número recuperado de vértebras, estos valores resultan poco representativos. Como era esperable, los huesos pequeños también presentan una elevada completitud. La cintura pélvica y la

1 Se mantiene la nomenclatura furrow en su idioma original debido a que no existe una traducción literal de este término, el cual refiere al mordisqueo de las epífisis, que escapular se registraron en general incompletas, en tanto que los huesos largos presentaron valores variables. En el caso de estos últimos, los resultados fueron significativamente menores para el conjunto generado por el gato montés, en relación al del zorro pampeano. Por último, los resultados en cuanto a la supervivencia intra-elemento indicaron que la misma fue variable, habiendo sido más afectadas las zonas de menor densidad mineral ósea, como algunas epífisis. En estos casos, las diáfisis adyacentes a las mismas también se vieron modificadas.

Los patrones de supervivencia diferencial de partes esqueletarias generados por gato montés y zorro pampeano son similares, lo cual indica que este aspecto por sí mismo no permite distinguir entre la acción de ambos carnívoros. Sólo se observaron diferencias en la representación de los miembros delanteros con respecto a los traseros, aspecto que por el momento no constituye una evidencia sólida que permita apoyar la identificación de uno u otro predador.

En un trabajo presentado recientemente, Massigoge et al. (2014) analizaron en detalle las marcas de dientes generadas en la muestra estudiada en este trabajo. Estos autores calcularon el porcentaje de modificaciones generado por ambos predadores, excluyendo a los elementos del autopodio, y determinaron que el mismo es mayor en el caso del zorro $(43,9 \%)$ que en el del gato $(35,5 \%)$. En relación con el tipo de marcas, la mayor frecuencia relativa para ambos predadores corresponde a los hoyuelos (gato montés $=54,4 \%$, zorro pampeano $=58,3 \%$ ), seguidos por los arrastres (gato montés $=24,5 \%$, zorro pampeano= $35,1 \%$ ), las perforaciones (gato montés $=14,9 \%$, zorro pampeano $=6,1 \%$ ), los bordes crenulados (gato montés $=5,9 \%$, zorro pampeano $=0,4 \%$ ) y los furrows ${ }^{1}$ (gato montés $=0,4 \%$, zorro pampeano= $0,1 \%$ ) (Massigoge et al. 2014).

$\mathrm{Al}$ igual que los patrones de supervivencia, las dimensiones de las marcas no demostraron ser un criterio útil para distinguir la acción de los carnivoros estudiados (Massigoge et al. 2014). Asimismo, tal como sucede con la representación diferencial de miembros anteriores y posteriores,

produce depresiones circulares que llegan a colapsar el tejido cortical (Haynes 1980). 
la frecuencia de los hoyuelos y arrastres constituye una posible vía de análisis que debe ser explorada en mayor profundidad. En este sentido, se destaca una frecuencia considerablemente mayor de estos tipos de marcas en los huesos largos afectados por el zorro en relación a los modificados por el gato montés. Estos resultados podrían ser explicados por algunas diferencias en el comportamiento alimenticio de los cánidos y los félidos. Estos últimos poseen una dentición especializada para el consumo de carne, con una mayor área de corte en sus molares carniceros, en tanto que el aparato masticatorio de los cánidos está vinculado a una dieta omnívora y posee una mayor área relativa de trituración (Zapata et al. 2008). Esto implica que los félidos tienden a producir un menor porcentaje de marcas por elemento, mientras que los cánidos, al alimentarse de los nutrientes internos del hueso, pueden generar un mayor número de modificaciones sobre la superficie cortical de los mismos (Selvaggio 1994; Domínguez-Rodrigo et al. 2007). Teniendo en cuenta las características eto-fisiológicas mencionadas, además de la mayor frecuencia de marcas, se esperaría también una mayor destrucción en la muestra no ingerida consumida por los cánidos, tal como sucedió con el resto de las modificaciones. Contrariamente, la fragmentación fue mayor para los restos óseos de conejos consumidos por el gato montés, cuya completitud fue del $15 \%$ en los huesos largos, en tanto que la del zorro fue de $51,2 \%$. Claramente, nuestros resultados no cumplen las expectativas generadas a partir de las conductas alimenticias diferenciales entre félidos y cánidos. En consecuencia, este aspecto aún no puede ser explicado y consideramos que es necesario ampliar las experimentaciones a otros individuos de gato y zorro, así como comparar estos resultados con los que se generen a partir de estudios actualísticos naturalistas.

Recientemente, algunos autores han enfatizado la necesidad de cotejar los experimentos llevados a cabo con animales en cautividad, con datos recabados en estudios naturalistas (Domínguez-Solera y Domínguez-Rodrigo 2009; Pickering et al. 2011; Gidna et al. 2013; Sala et al. 2013). Esto se debe a que en algunos casos, en ausencia de las presiones selectivas propias de los ambientes naturales, los animales desarrollan comportamientos artificiales para pasar el tiempo, como por ejemplo el masticado de huesos. Esto influye en las modificaciones generadas en los especímenes $y$, en algunas oportunidades, se produciría un aumento en la frecuencia de marcas registradas (Gidna et al. 2013). Más allá de esto, creemos que los modelos experimentales aportan valiosa información en algunos aspectos que se verían menos afectados por las condiciones ecológicas, tales como el tamaño de los hoyuelos y los patrones de disolución química generados por los ácidos gástricos. Por otro lado, hasta el presente los estudios tafonómicos que comparan las modificaciones óseas producidas por animales en cautividad vs. en ambientes naturales tienen escaso desarrollo y se han aplicado a muy pocas especies, como los félidos de gran tamaño (i.e., leones y leopardos; Pobiner 2008; Pickering et al. 2011; Gidna et al. 2013) y los lobos (Sala et al. 2013). Por el momento, no disponemos de datos que permitan comparar nuestros resultados experimentales con aquellos resultantes del estudio de muestras naturalistas.

La Tabla 4 constituye un resumen de las investigaciones realizadas en Argentina sobre los patrones de modificación ósea producidos por distintos predadores autóctonos. A partir de esta información se discuten algunas similitudes y diferencias generales entre los animales estudiados y los disponibles en la literatura. En primer lugar, considerando los mamíferos carnívoros, los tipos de marcas y patrones de fracturas registrados no permiten diferenciar entre especies, familias o incluso categorías más amplias, como carnívoros grandes (Puma concolor) y pequeños $(\leq 15$ $\mathrm{kg}$ ). En este sentido, si bien esperábamos poder distinguir patrones de modificación ósea para félidos y cánidos, esto no fue posible. Por otro lado, recientemente se han desarrollado análisis detallados que evalúan los tamaños de los hoyuelos generados por distintos predadores (Delaney Rivera et al. 2009; Massigoge et al. 2014). Estos estudios también señalan la dificultad de diferenciar en el registro fósil los agregados originados por distintos grupos taxonómicos. Sin embargo, pueden encontrarse algunas diferencias en las dimensiones de las marcas, aunque las mismas están vinculadas al tamaño del predador y no al tipo de dentición (i.e., cánidos us. félidos) (Delaney Rivera et al. 
Tabla 4. Modificaciones registradas para distintos predadores de Argentina. Sólo se incluyeron referencias con datos acerca de las modificaciones generadas en los restos estudiados.

\begin{tabular}{|c|c|c|c|c|}
\hline Predadores & Nombre científico & Muestra & Daños registrados & Fuente \\
\hline \multirow{7}{*}{ 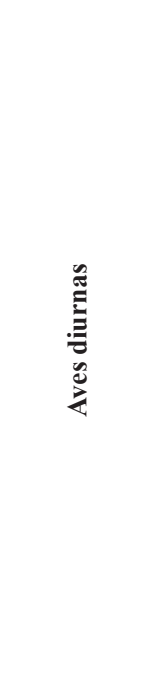 } & $\begin{array}{l}\text { Coragips atratus } \\
\text { (Jote de cabeza negra) }\end{array}$ & $\begin{array}{l}469 \text { egagrópilas de } \\
\text { campo }\end{array}$ & $\begin{array}{l}\text { Evidencias de digestión gástrica. } \\
\text { Perforaciones, fracturas y poceado }\end{array}$ & Ballejo et al. (2012) \\
\hline & \multirow{4}{*}{$\begin{array}{l}\text { Caracara plancus } \\
\text { (Carancho) }\end{array}$} & $\begin{array}{l}2 \text { egagrópilas de } \\
\text { zoológico }\end{array}$ & Evidencias de digestión gástrica & Gómez (2007) \\
\hline & & $\begin{array}{l}65 \text { restos no ingeridos } \\
\text { y } 67 \text { egagrópilas de } \\
\text { campo }\end{array}$ & \multirow{3}{*}{$\begin{array}{l}\text { Restos no ingeridos: fracturas } \\
\text { escalonadas, longitudinales y en } \\
\text { espiral. Perforaciones con bordes } \\
\text { redondeados o sub-redondeados a } \\
\text { lo largo del borde. } \\
\text { Egagrópilas: evidencias de } \\
\text { digestión gástrica }\end{array}$} & $\begin{array}{l}\text { Montalvo y Tallade } \\
\qquad(2009)\end{array}$ \\
\hline & & $\begin{array}{c}76 \text { restos no ingeridos } \\
\text { de campo }\end{array}$ & & $\begin{array}{l}\text { Montalvo y Tallade } \\
\text { (2010) }\end{array}$ \\
\hline & & $\begin{array}{l}76 \text { restos no ingeridos } \\
\text { y } 23 \text { egagrópilas de } \\
\text { campo }\end{array}$ & & Montalvo et al. (2011) \\
\hline & $\begin{array}{c}\text { Circus buffoni (Gavilán } \\
\text { planeador) }\end{array}$ & 4 egagrópilas de campo & Evidencias de digestión gástrica & Gómez (2007) \\
\hline & $\begin{array}{l}\text { Mivalgo chimango } \\
\text { (Chimango) }\end{array}$ & $\begin{array}{c}2 \text { egagrópilas de } \\
\text { zoológico }\end{array}$ & Evidencias de digestión gástrica & Gómez (2007) \\
\hline \multirow{6}{*}{ 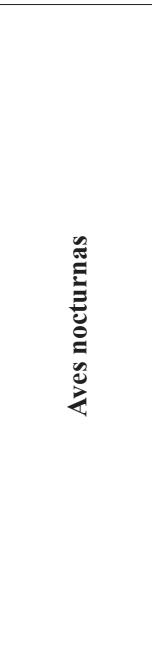 } & $\begin{array}{l}\text { Bubo virginianus } \\
\text { (Ñacurutú) }\end{array}$ & $\begin{array}{l}9 \text { egagrópilas de } \\
\text { zoológico }\end{array}$ & Evidencias de digestión gástrica & Gómez (2007) \\
\hline & & 4 egagrópilas de campo & Evidencias de digestión gástrica & Gómez (2007) \\
\hline & $\begin{array}{c}\text { Tyto alba } \\
\text { (Lechuza de campanario) }\end{array}$ & $\begin{array}{l}58 \text { egagrópilas de } \\
\text { campo y material } \\
\text { disgregado }\end{array}$ & Evidencias de digestión gástrica & Fernández et al. (2009) \\
\hline & $\begin{array}{c}\text { Athene cunicularia } \\
\text { (Lechuza de las } \\
\text { vizcacheras) }\end{array}$ & $\begin{array}{l}11 \text { egagrópilas de } \\
\text { zoológico }\end{array}$ & Evidencias de digestión gástrica & Gómez (2007) \\
\hline & $\begin{array}{c}\text { Asio flammeus } \\
\text { (Lechuzón de campo) }\end{array}$ & 1 egagrópila de campo & Evidencias de digestión gástrica & Gómez (2007) \\
\hline & $\begin{array}{c}\text { Asio clamator (Lechuzón } \\
\text { orejudo) }\end{array}$ & $\begin{array}{c}25 \text { Mus musculus } \\
\text { ofrecidos (11 } \\
\text { egagrópilas) en parque } \\
\text { provincial }\end{array}$ & $\begin{array}{l}\text { Evidencias de digestión gástrica. } \\
\text { Escasas fracturas }\end{array}$ & $\begin{array}{l}\text { Carrera y Fernández } \\
\qquad(2010)\end{array}$ \\
\hline \multirow{5}{*}{ 葛 } & \multirow{5}{*}{ Puma concolor (Puma) } & 2 fecas de zoológico & Evidencias de digestión gástrica & Gómez (2007) \\
\hline & & 76 fecas de campo & $\begin{array}{l}\text { Evidencias de digestión gástrica. } \\
\text { Marcas y surcos producidos por } \\
\text { dientes }\end{array}$ & Montalvo et al. (2007) \\
\hline & & $\begin{array}{l}\text { Más de } 70 \text { carcasas de } \\
\text { guanaco de campo }\end{array}$ & $\begin{array}{c}\text { Restos no ingeridos: Perforaciones, } \\
\text { hoyuelos, bordes crenulados } \\
\text { (festoneados), fracturas }\end{array}$ & Borrero et al. (2005) \\
\hline & & $\begin{array}{c}\text { Diferentes muestras } \\
\text { de campo (transectas } \\
\text { y madrigueras) sin } \\
\text { número }\end{array}$ & $\begin{array}{l}\text { Perforaciones, festoneado, bordes } \\
\text { crenulados, arrastres, fracturas, } \\
\text { mordeduras superpuestas }\end{array}$ & $\begin{array}{l}\text { Borrero y Martin } \\
\qquad(1996)\end{array}$ \\
\hline & & $\begin{array}{l}140 \text { huesos de ovejas } \\
\text { y liebres }\end{array}$ & $\begin{array}{l}\text { Perforaciones, bordes crenulados, } \\
\text { estrías, fracturas, cilindros, } \\
\text { astillado }\end{array}$ & $\begin{array}{l}\text { Martin y Borrero } \\
\text { (1997) }\end{array}$ \\
\hline
\end{tabular}




\begin{tabular}{|c|c|c|c|c|}
\hline Predadores & Nombre científico & Muestra & Daños registrados & Fuente \\
\hline 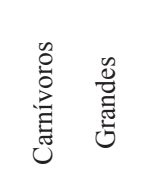 & & $\begin{array}{l}128 \text { especímenes de } \\
\text { guanaco }\end{array}$ & $\begin{array}{l}\text { Arrastres, perforaciones, hoyuelos, } \\
\text { improntas de dientes, bordes } \\
\text { crenulados, triturado, fracturas }\end{array}$ & Muñoz et al. (2008) \\
\hline & & 9 carcasas de guanaco & Perforaciones & Kaufmann (2009) \\
\hline \multirow{13}{*}{ 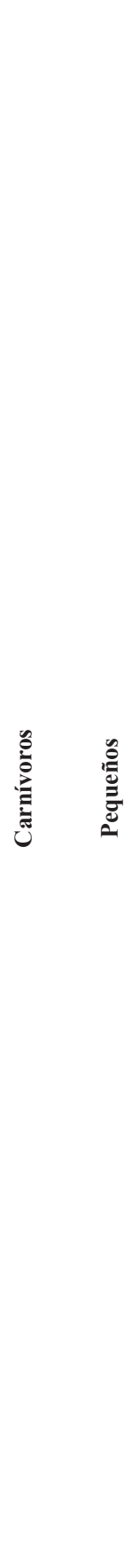 } & \multirow{2}{*}{$\begin{array}{c}\text { Lycalopex griseus } \\
\text { (Zorro gris) y Lycalopex } \\
\text { culpaeus (Zorro } \\
\text { colorado) }\end{array}$} & 16 fecas de campo & Evidencias de digestión gástrica & Mondini (2000) \\
\hline & & 62 fecas de campo & Evidencias de digestión gástrica & Mondini (2004) \\
\hline & $\begin{array}{c}\text { Lycalopex griseus } \\
\text { (Zorro gris) y Lycalopex } \\
\text { culpaeus (Zorro } \\
\text { colorado) }\end{array}$ & $\begin{array}{l}7 \text { madrigueras de } \\
\text { campo (121 huesos) }\end{array}$ & Perforaciones & Mondini (1995) \\
\hline & & 2 fecas de zoológico & Evidencias de digestión gástrica & Gómez (2007) \\
\hline & $\begin{array}{l}\text { Lycalopex gymnocercus } \\
\text { (Zorro pampeano) }\end{array}$ & $\begin{array}{c}\text { Tres miembros } \\
\text { delanteros y parte del } \\
\text { esqueleto axial de } \\
\text { oveja en un hábitat } \\
\text { controlado }\end{array}$ & $\begin{array}{l}\text { Arrastres, hoyuelos, perforaciones, } \\
\text { remoción ósea sustancial }\end{array}$ & Elkin y Mondini (2001) \\
\hline & $\begin{array}{l}\text { Lycalopex griseus } \\
\text { (Zorro gris) }\end{array}$ & 59 fecas de campo & $\begin{array}{l}\text { Evidencias de digestión gástrica. } \\
\text { Perforación }\end{array}$ & $\begin{array}{l}\text { Gómez y Kaufmann } \\
\text { (2007) }\end{array}$ \\
\hline & Conepatus chinga & 2 fecas de campo & Evidencias de digestión gástrica & Gómez (2007) \\
\hline & (Zorrino) & 372 fecas de campo & $\begin{array}{c}\text { Evidencias de digestión gástrica. } \\
\text { Marca de diente }\end{array}$ & Montalvo et al. (2008) \\
\hline & & 2 fecas de campo & Evidencias de digestión gástrica & Gómez (2007) \\
\hline & & 179 fecas de campo & Evidencias de digestión gástrica & Montalvo et al. (2012) \\
\hline & $\begin{array}{l}\text { Leopardus geoffroyi } \\
\qquad \text { (Gato montés) }\end{array}$ & $\begin{array}{l}\text { Restos no ingeridos de } \\
10 \text { Oryctolagus } \\
\text { cuniculus ofrecidos en } \\
\text { zoológico }\end{array}$ & $\begin{array}{l}\text { Hoyuelos, perforaciones, bordes } \\
\text { crenulados, arrastres }\end{array}$ & Álvarez et al. (2012) \\
\hline & $\begin{array}{l}\text { Didelphis albiventris } \\
\text { (Comadreja overa) }\end{array}$ & 2 fecas de zoológico & Evidencias de digestión gástrica. & Gómez (2007) \\
\hline & $\begin{array}{c}\text { Herpailurus } \\
\text { yagouaroundi (Gato } \\
\text { yaguarundí) }\end{array}$ & 3 fecas de zoológico & Evidencias de digestión gástrica & Gómez (2007) \\
\hline
\end{tabular}


Tabla 5. Daños registrados en restos óseos consumidos procedentes de colecciones experimentales y etnoarqueológicas realizadas en grupos humanos en distintas regiones del mundo.

\begin{tabular}{|c|c|c|c|c|}
\hline Tipo de estudio & Grupo estudiado & $\begin{array}{c}\text { Muestra y taxones } \\
\text { estudiados }\end{array}$ & Daños registrados & Fuente \\
\hline Muestra etnoarqueológica & $\begin{array}{c}\text { Nukak (Amazonía } \\
\text { Colombiana) }\end{array}$ & $\begin{array}{l}\text { Mono (más de ocho } \\
\text { especies) y pecarí } \\
\text { labiado (Tayassu } \\
\text { pecari) }\end{array}$ & $\begin{array}{l}\text { Arrastres, ahuecado, bordes } \\
\text { crenulados, } \\
\text { grietas longitudinales, } \\
\text { perforaciones y hoyuelos }\end{array}$ & Martínez (2009) \\
\hline Experimento & - & Oveja (Ovis aries) & $\begin{array}{l}\text { Arrastres, hoyuelos, } \\
\text { perforaciones, remoción } \\
\text { ósea sustancial }\end{array}$ & $\begin{array}{l}\text { Elkin y Mondini } \\
\text { (2001) }\end{array}$ \\
\hline Experimento & - & $\begin{array}{c}\text { Oveja (Ovis aries), } \\
\text { chancho (Sus scrofa) } \\
\text { y conejo (Oryctolagus } \\
\text { cuniculus) }\end{array}$ & $\begin{array}{c}\text { Arrastres, ahuecado, } \\
\text { bordes crenulados, grietas } \\
\text { longitudinales, } \\
\text { triturado, exfoliado/ } \\
\text { extremos curvados, } \\
\text { hoyuelos, perforaciones }\end{array}$ & Saladié et al. (2013) \\
\hline Muestra etnoarqueológica & $\begin{array}{c}\text { Bofi (República Africana } \\
\text { Central) }\end{array}$ & $\begin{array}{c}\text { Duiker azul } \\
\text { (Philantomba } \\
\text { monticola) } \\
\text { Rata gigante } \\
\text { (Cricetomys } \\
\text { gambianus) } \\
\text { Puerco espín cola de } \\
\text { cepillo } \\
\text { (Atherurus } \\
\text { africanus) } \\
\text { Múridos y ratones }\end{array}$ & $\begin{array}{l}\text { Bordes crenulado, grietas } \\
\text { longitudinales, hoyuelos, } \\
\text { perforaciones, arrastres }\end{array}$ & Landt (2007) \\
\hline Experimento & - & $\begin{array}{c}\text { Conejo } \\
\text { (Oryctolagus } \\
\text { cuniculus) }\end{array}$ & $\begin{array}{l}\text { Bordes crenulados, } \\
\text { hoyuelos, arrastres }\end{array}$ & Lloveras et al. (2009) \\
\hline Experimento & - & $\begin{array}{c}\text { Chancho (Sus scrofa) } \\
\text { y oveja (Ovis aries) }\end{array}$ & $\begin{array}{l}\text { Arrastres, bordes } \\
\text { crenulados, triturado }\end{array}$ & Fernández-Jalyo y \\
\hline Muestra etnoarqueológica & $\begin{array}{l}\text { Koi (Desierto de } \\
\text { Namibia) }\end{array}$ & Oveja (Ovis aries) & $\begin{array}{l}\text { exfoliado/extremos } \\
\text { curvados, hoyuelos }\end{array}$ & Andrews (2011) \\
\hline Muestra etnoarqueológica & $\begin{array}{c}\text { Hotentotes } \\
\text { (Sudoeste de África) }\end{array}$ & Cápridos (Capra) & Arrastres & Brain (1981) \\
\hline Muestra etnoarqueológica & $\begin{array}{l}\text { Nunamiut (Norte y } \\
\text { Noroeste de Alaska) }\end{array}$ & $\begin{array}{c}\text { Caribou (Rangifer } \\
\text { tarandus) }\end{array}$ & $\begin{array}{l}\text { Bordes crenulados, } \\
\text { grietas longitudinales }\end{array}$ & Binford (1981) \\
\hline Muestra etnoarqueológica & $\begin{array}{c}\text { Aché (región oriental del } \\
\text { Paraguay) }\end{array}$ & Animales $<15 \mathrm{~kg}$ & Arrastres, ahuecado & Jones $(1983,1993)$ \\
\hline Muestra etnoarqueológica & $\begin{array}{c}\text { Dassanetch (lago } \\
\text { Turkana) }\end{array}$ & Cápridos (Capra) & $\begin{array}{c}\text { Ahuecado, triturado, } \\
\text { arrastres }\end{array}$ & $\begin{array}{l}\text { Gifford-Gonzalez } \\
\text { (1989) }\end{array}$ \\
\hline Muestra etnoarqueológica & Hadza (Tanzania central) & $\begin{array}{l}\text { Distintas especies de } \\
\text { ungulados africanos }\end{array}$ & $\begin{array}{c}\text { Ahuecado, exfoliado/ } \\
\text { extremos curvados, } \\
\text { hoyuelos }\end{array}$ & Oliver (1993) \\
\hline
\end{tabular}


2009; Andrés et al. 2012).

$\mathrm{Si}$ bien nuestros resultados no permiten diferenciar entre especies del Orden Carnivora, los patrones observados en este trabajo aportan nuevos datos (i.e., supervivencia esqueletaria, tipo $y$ frecuencia de marcas) que ayudan a distinguir estos conjuntos de aquellos originados por otros predadores como por ejemplo, aves rapaces diurnas (falcónidos; i.e., halcones y caranchos) y nocturnas (estrígidos y asiónidos; i.e., búhos y lechuzas). Tanto las aves como los mamíferos carnivoros generan conjuntos integrados por restos no ingeridos e ingeridos (egagrópilas y fecas, respectivamente). Sin embargo, en el caso de los restos ingeridos, una de las principales diferencias entre ambas clases la constituye la fragmentación de los restos. Las aves rapaces tienden a ingerir presas o unidades anatómicas completas, en tanto que los carnívoros fracturan los restos con sus dientes antes de ingerirlos (Andrews 1990; Pardiñas 1999). Por otro lado, estos conjuntos presentan evidencias de digestión gástrica, la cual suele ser más fuerte en los carnivoros y moderada y leve en las aves. En el caso de los restos no ingeridos, los conjuntos generados por las aves suelen presentar escasas modificaciones óseas. No obstante, algunos autores mencionan la presencia de fracturas y pérdida ósea por aves rapaces que producen perforaciones con sus picos y garras (Montalvo et al. 2011; Lloveras et al. 2014). Con respecto a los mamíferos carnívoros, los restos no ingeridos presentan mayores frecuencias de modificaciones, las cuales son características de este Orden, tales como los arrastres, hoyuelos, furrows y cilindros óseos.

Otro punto a considerar es que los estudios etnoarqueológicos y experimentales llevados a cabo con grupos humanos también informan que estos generan marcas dentarias sobre los restos óseos. En la Tabla 5 se presenta una síntesis de los tipos de modificaciones óseas generadas por los humanos, tanto en trabajos etnoarqueológicos como en experimentaciones controladas. Las marcas de este agente son distinguibles de aquellas generadas por aves rapaces, pero podrían ser

2 La rotura por la flexión de las piezas con las manos o por el masticado con los dientes de la mejilla y curvando el hueso con las manos produce un tipo particular de exfoliado, con una superficie rugosa y una textura fibrosa. Cuando este confundidas con aquellas producidas por mamíferos carnivoros pequeños y medianos. En este sentido, los huesos consumidos por los humanos, así como aquellos observados en experimentaciones actuales, presentan evidencias de marcas tales como hoyuelos, perforaciones y arrastres, entre otras (ver citas en Tabla 5). Sin embargo, otras modificaciones, como por ejemplo los extremos curvados $^{2}$ y algunos tipos de hoyuelos (e.g., en forma de medialuna), podrían ser diagnósticas para diferenciar al agente humano de otros animales (Fernández-Jalvo y Andrews 2011). Esto alerta acerca de una potencial equifinalidad entre las marcas resultantes del consumo humano y aquellas generadas por otros predadores, aspecto que ha sido escasamente considerado en los estudios tafonómicos de conjuntos arqueofaunísticos, como ha sido previamente mencionado por otros investigadores, como Elkin y Mondini (2001) y Delaney-Rivera et al. (2009).

En síntesis, este trabajo demuestra la importancia de generar modelos actualísticos que consideren en forma integral y detallada las modificaciones generadas por diferentes agentes tafonómicos. La combinación de estos criterios permite afinar las inferencias acerca del/los predadores que generaron un conjunto dado. Esta información es útil a la hora de evaluar el rol de los agentes naturales y su incidencia en la configuración del registro arqueológico. Finalmente, en esta fase de nuestra investigación nos hemos concentrado en el desarrollo de estudios experimentales con el objetivo de conocer los tipos de modificaciones generadas por los carnivoros que se encuentran presentes en nuestras regiones de estudio arqueológico. Sin embargo, parte de las experiencias futuras estarán orientadas a la recolección de datos naturalistas, con el objetivo de comparar las muestras experimentales y de campo y así evaluar en mayor profundidad la utilidad de nuestros modelos en la interpretación del registro arqueológico.

\section{AGRADECIMIENTOS}

exfoliado se presenta en los huesos delgados (e.g., costillas) se produce una forma característica, cuyos extremos son curvados (bent ends) (Fernández-Jalvo \& Andrews 2011; Saladié et al. 2013). 
Este estudio es desarrollado dentro del programa de investigaciones INCUAPA-CONICET (Facultad de Ciencias Sociales, UNCPBA) y es financiado por CONICET (PIP 112-20080100291) y ANPCyT (PICT 08-814). Agradecemos especialmente al personal del Parque Zoológico La Máxima (Municipalidad de Olavarría) por su colaboración durante la realización de los experimentos; particularmente, a Horacio Grandt y Agustín Venzi. Las ideas vertidas en este trabajo son de exclusiva responsabilidad de los autores.

\section{BIBLIOGRAFÍA}

Acosta, A., \& Pafundi, L. (2005). Zooarqueología y tafonomía de Cavia aperea en el humedal del Paraná inferior. Intersecciones en Antropología 6, 59-74.

Álvarez, M. C. (2009). Análisis de los restos faunísticos del sitio Calera (Sierras Bayas, Partido de Olavarría). Un aporte a su funcionalidad a través del estudio de los mamíferos. Relaciones de la Sociedad Argentina de Antropología XXXIV, 29-51.

Álvarez, M. C., Kaufmann, C. A., Massigoge, A., Gutiérrez, M. A., Rafuse, D. J., Scheifler, N. A., \& González, M. E. (2012). Bone modification and destruction patterns of leporid carcasses by Geoffroy's cat (Leopardus geoffroyi): An experimental study. Quaternary International 278, 71-80.

Andrés, M., Gidna, A., Yravedra, J., \& Domínguez-Rodrigo, M. (2012). A study of dimensional differences of tooth marks (pits and scores) on bones modified by small and large carnivores. Archaeological and Anthropological Sciences 4, 209-219.

Andrews, P. (1990). Owls, caves and fossils. Predation, preservation, and accumulation of small mammal bones in caves, with the analysis of the Pleistocene cave faunas from Westbury-sub-Mendip. Somerset: The University of Chicago Press.

Ballejo, F., Fernández, F. J., \& De Santis, L. J. M. (2012). Tafonomía de restos óseos provenientes de egagrópilas de Coragyps atratus (jote de cabeza negra) en el Noroeste de la Patagonia argentina. Revista del Museo de Antropología 5, 213-222.

Bastourre, M. L., \& Salazar Siciliano, G. (2012). Análisis arqueofaunístico del sitio 5 de la localidad Tapera Moreira (departamento de Lihué Calel, provincia de La Pampa). Interseccciones en Antropología 13, 269280.

Binford, L. R. (1981). Bones: Ancient men and modern myths. New York: Academic Press.

Bonomo, M. (2006). Un acercamiento a la dimensión simbólica de la cultura material en la región pampeana. Relaciones de la Sociedad Argentina de Antropología XXXI, 89-115.

Borrero, L. A, \&, Martin, F. M. (1996). Tafonomía de carnivoros: un enfoque regional. En J. Gómez Otero (Ed.), Arqueología. Sólo Patagonia (pp. 189-206). Puerto Madryn: CENPAT (CONICET).

Borrero, L. A., Martin, F. M., \& Vargas, J. (2005). Tafonomía de la interacción entre pumas y guanacos en el Parque Nacional Torres del Paine, Chile. Magallania 33 (1), 95-114.

Brain, C. K. (1981). The hunters of the hunted? An introduction to African cave taphonomy. Chicago and London: The University of Chicago Press.

Cabrera, A., \& Yepes, J. (1960). Mamíferos sudamericanos. Buenos Aires: Ediar.

Carrera, J. D., \& Fernández, F. J. (2010). Análisis tafonómico de egagrópilas producidas por el lechuzón orejudo (Asio clamator): un caso experimental. En M. A. Gutiérrez, M. De Nigris, P. Fernández, M. Giardina, A. Gil, A. Izeta, G. Neme, \& H. Yacobaccio (Eds.), Zooarqueología a principios del siglo XXI: Aportes teóricos, metodológicos y casos de estudio (pp. 381386). Ayacucho: Libros del Espinillo.

Castillo, D. F., Birochio, D., Lucherini, M, \& Casanave, E. (2011). Diet of adults and cubs of Lycalopex gymnocercus in Pampas grasslands: a validation of the Optimal Foraging Theory? Annales Zoologici Fennici 48, 251-256.

Christiansen, P., \& Wroe, S. (2007). Bite forces and evolutionary adaptations to feeding ecology in Carnivores. Ecology 88 (2), 347-358.

Cochard, D. (2008). Discussion sur la variabilité intraréférentiel d’accumulations osseuses de petits prédateurs. Annales de Paléonotologie 94, 89-101.

Delaney-Rivera, C., Plummer, T. W., Hodgson, J. A., Forrest, F, Hertel, F, \& Oliver, J. S. (2009). Pits and pitfalls: taxonomic variability and patterning in tooth mark dimensions. Journal of Archaeological Science 36, 2597-2608.

Domínguez-Rodrigo, M., Egeland, C. P., \& Pickering, T. R. (2007). Models of passive scavenging by early hominids: problems arising from equifinality in carnivore tooth mark frequencies and the extended concept of archaeological palimpsests. En T. Pickering, K. Schick, \& N. Toth (Eds.), Breathing life into Fossils: Taphonomic studies in honor of C. K. (Bob) Brain 
(pp. 255-268). Gosport: Stone Age Institute Publication Series, Stone Age Institute Press.

Domínguez-Solera, S., \& Domínguez-Rodrigo, M. (2009). A taphonomic study of bone modification and of toothmark patterns on long limb bone portions by suids. International Journal of Osteoarchaeology 19, 345363.

Elkin, D., \& Mondini, M. (2001). Human and small carnivore gnawing damage on bones. An exploratory study and its archaeological implications. En L.A. Kuznar (Ed.), Ethnoarchaeology of Andean South America: Contributions to Archaeological Method and Theory (pp. 255-265). Ann Arbor: International Monographs in Prehistory.

Escosteguy, P. D., Salemme, M., \& González, M. I. (2012). Myocastor coypus ("coipo", Rodentia, Mammalia) como recursos en los humedales de la Pampa bonaerense: patrones de explotación. Revista del Museo de Antropología 5, 13-30.

Fernández-Jalvo, Y., \& Andrews, P. (1992). Small mammal taphonomy of Gran Dolina, Atapuerca (Burgos), Spain. Journal of Archaeological Science 19, 407-428.

Fernández-Jalvo, Y., \& Andrews, P. (2011). When humans chew bones. Journal of Human Evolution 60, 117 123.

Fernández, F. J., Moreira, G., Ballejo, F. \& De Santis, L. (2009). Novedosos registros de aves exhumadas del sitio arqueológico Laguna El Sosneado (LS-3) para el Holoceno tardío en el sur de Mendoza: aspectos tafonómicos. Intersecciones en Antropología 10, 311-326.

Gifford-González, D. (1989). Overview-modern analogues: Developing an interpretative framework. En R. Bonnichsen, \& M. H. Sorg (Eds.), Bone modification (pp. 43-52). Orono: University of Maine, Center for the Study of the First Americans.

Gidna, A., Yravedrac, J., \& Domínguez-Rodrigo, M. (2013). A cautionary note on the use of captive carnivores to model wild predator behavior: a comparison of bone modification patterns on long bones by captive and wild lions. Journal of Archaeological Science 40, 19031910.

Gómez, G. (2007). Predators categorization based on taphonomic analysis of micromammals bones: a comparison to proposed models. En M. A. Gutiérrez, L. Miotti, G. Barrientos, G. Mengoni Goñalons, \& M. Salemme (Eds.), Taphonomy and Zooarchaeology in Argentina (pp. 89-103). BAR S1601 (British Archaeological Report).
Gómez, G., \& Kaufmann, C. A. (2007). Taphonomic analysis of Pseudalopex griseus (Gray, 1837) scat assemblages and their archaeological implications. Journal of Taphonomy 5, 59-70.

Haynes, G. (1980). Evidence of carnivore gnawing on Pleistocene and recent mammalian bones. Paleobiology 6, 341-351.

Johnson, W. E., \& Franklin, W. L. (1991). Feeding and spatial ecology of Geoffroy's cat (Felis geoffroyi) in southern Patagonia. Journal of Mammalogy 72, 815-820.

Jones, K. T. (1983). Forager archaeology: The Aché of Eastern Paraguay. En G.M. Lemoine, \& A. S. MacEachern (Eds.), Carnivores, human scavengers, and predators: a question of bone technology (pp. 101-114). Calgary: Archaeological Association, University of Calgary.

Jones, K. T. (1993). The archaeological structure of a short-term camp. En J. Hudson (Ed.), From bones to behavior (pp. 101-114). Illinois: Center for Archaeological Investigations.

Kaufmann, C. A. (2009). Estructura de Edad y Sexo en Lama guanicoe (Guanaco). Estudios actualísticos y arqueológicos en Pampa y Patagonia. Buenos Aires: Sociedad Argentina de Antropología.

Labarca, R. (2005). Las vizcachas de Piuquenes: evidencias de explotación de roedores durante la transición Pleistoceno-Holoceno en la cordillera andina de Chile Central. Revista Werken 6, 63-80.

Landt, M. J. (2007). Tooth marks and human consumption: ethnoarchaeological mastication research among foragers of the Central African Republic. Journal of Archaeological Science 34, 1629-1640.

Lloveras, L., Moreno-García, M. \& Nadal, J. (2008). Taphonomic analysis of leporid remains obtained from modern Iberian lynx (Lynx pardinus) scats. Journal of Archaeological Science 35, 1-13.

Lloveras, L., Moreno-García, M., \& Nadal, J. (2009). Butchery, cooking and human consumption marks on rabbit (Oryctolagus cuniculus) bones: an experimental study. Journal of Taphonomy 7, 179-201.

Lloveras, L., Nadal, J., Moreno-García, M., Thomas, R., Anglada, J., Baucells, J., Martorell, C., \& Vilasís, D. (2014). The role of the Egyptian Vulture (Neophron percnopterus) as a bone accumulator in cliff rock shelters: an analysis of modern bone nest assemblages from North-eastern Iberia. Journal of Archaeological Science 44, 76-90.

Lucherini, M., \& Luengos Vidal, E. M. (2008). Lycalopex gymnocercus (Carnivora: Canidae). Mammalian Species 820, 1-9. 
Lucherini, M., Pessino, M., \& Farias, A. A. (2004). Pampas fox. En C. Sillero-Zubiri, M. Hoffman, \& D. W. Macdonald (Eds.), editors Canids: foxes, wolves, jackals, and dogs. Status survey and conservation action plan (pp. 63-68). Gland: Switzerland International Union for Conservation of Nature and Natural Resources/Species Survival Commission Canid Specialist Group.

Lucherini, M., Manfredi, M., Luengos, C., Días Masim, E., Soler, F., \& Casenave, E. (2006). Body mass variation in the Geoffroy's cat (Oncifelis geoffroyi). Revista Chilena de Historia Natural 79, 169-174.

Manfredi, C., Lucherini, M., Canepuccia, A., \& Casanave, E. (2004). Geographical variations in the diet composition of the Geoffroy's cat (Oncifelis geoffroyi) in the pampas. Journal of Mammalogy 85, 1111-1115.

Manfredi, C., Lucherini, M., Soler, L., Baglioni, J., Luengos Vidal, E., \& Casanave, E. (2011). Activity and movement patterns of Geoffroy's cat in the grasslands of Argentina. Mammalian Biology 76, 313-319.

Marean, C. W. (1995). Of taphonomy and zooarchaeology. Evolutionary Anthropology 4 (2), 64-72.

Marean, C. W., Yoshiko, A., Nilssen, P. J., \& Stone, E. C. (2001). Estimating the minimum number of skeletal elements (MNE) in zooarchaeology: a review and a new image-analysis GIS approach. American Antiquity 66 (2), 333-348.

Martin, F. M., \& Borrero, L. A. (1997). A puma lair in southern Patagonia: implications for the archaeological record. Current Anthropology 38 (3), 453-461.

Martínez, G. (2009). Human chewing bone surface modification and processing of small and medium prey amongst the Nukak (foragers of the Colombian Amazon). Journal of Taphonomy 7, 1-20.

Martínez, G., \& Gutiérrez, M. A. (2004). Tendencias en la explotación humana de la fauna durante el Pleistoceno final y Holoceno en la Región Pampeana (Argentina). En G. Mengoni Goñalons (Ed.), Zooarchaeology of South America (pp. 81-98). Oxford: BAR International Series 1298.

Massigoge, A., Gutiérrez M. A., Álvarez, M. C., Kaufmann, C. A., Rafuse, D., \& González, M. E. (2014). Estudio comparativo de las marcas de dientes producidas por dos pequeños carnívoros sudamericanos. Revista Chilena de Antropología. En prensa.

Mazzanti, D., \& Quintana, C. (2001). Cueva Tixi: cazadores $y$ recolectores de las sierras de Tandilia Oriental. Geología, paleontología y zooarqueología. Mar del Plata: Laboratorio de Arqueología, Universidad Nacional de Mar del Plata, Publicación Especial 1.
Medina, M., Rivero, D., \& Teta, P. (2011). Consumo antrópico de pequeños mamíferos en el Holoceno de Argentina Central: perspectivas desde el abrigo rocoso Quebrada del Real 1 (Pampa de Achala, Córdoba. Latin American Antiquity 22 (4), 615-628.

Miotti, L., \& Salemme, M. (1999). Biodiversity, taxonomic richness and specialists-generalists during Late Pleistocene/Early Holocene times in Pampa and Patagonia (Argentina, Southern South America). Quaternary International 53/54, 53-68.

Mondini, M. (1995). Artiodactyl prey transport by foxes in Puna rock shelters. Current Anthropology 36 (3), 520-524.

Mondini, M. (2000). Tafonomía de abrigos rocosos de la Puna. Formación de conjuntos escatológicos por zorros y sus implicaciones arqueológicas. Archaeofauna 9, 151164.

Mondini, M. (2004). Accumulation of small and large vertebrates by carnivores in Andean South America. En J. P. Brugal, \& J. Desse (Eds.), Petits animaux et sociétés humaines. Du complément alimentaire aux ressources utilitaires (pp. 513-517). Antibes: Éditions APDCA.

Mondini, M. (2011). Tafonomía de carnívoros en los Andes centro-sur. Madrigueras actuales y sus implicaciones para el registro arqueofaunístico. En A. Acosta, D. Loponte, \& L. Mucciolo (Eds.), Temas de Arqueología: Estudios Tafonómicos y Zooarqueológicos (II) (pp. 67-105). Buenos Aires: Asociación de Amigos del Instituto Nacional de Antropología y Pensamiento Latinoamericano.

Mondini, M., \& Muñoz, S. (2011). Aproximaciones y escalas de análisis en la zooarqueología y tafonomía sudamericanas. Algunas reflexiones sobre su estado actual y perspectivas para su desarrollo. Antipoda. Revista de Antropología y Arqueología 13, 229-250.

Montalvo, C. I., \& Tallade, P. O. (2009). Taphonomy of the accumulations produced by Caracara plancus (Falconidae). Analysis of prey remains and pellets. Journal of Taphonomy 7, 235-248.

Montalvo, C. I., \& Tallade, P. O. (2010). Análisis tafonómico de restos no ingeridos de roedores presa de Caracara plancus (Aves, Falconidae). En M. De Nigris, P. Fernández, M. Giardina, A. Gil, M. A Gutiérrez, A. Izeta, G. Neme, \& H. Yacobaccio (Eds.), Zooarqueología a principios del siglo XXI: aportes teóricos, metodológicos y casos de estudio (pp. 419428). Buenos Aires: Ediciones del Espinillo.

Montalvo, C. I., Pessino, M. E., \& González, V. H. (2007). Taphonomic analysis of remains of mammals eaten by 
pumas (Puma concolor, Carnivora, Felidae) in central Argentina. Journal of Archaeological Science 34, 2151-2160.

Montalvo, C. I., Pessino, M. E., \& Bagatto, F. C. (2008). Taphonomy of the bones of rodents consumed by Andean hog-nosed skunks (Conepatus chinga, Carnivora, Mephitidae) in central Argentina. Journal of Archaeological Science 35, 1481-1488.

Montalvo, C. I., Bisceglia, S., Kin, M. S, \& Sosa, R. A. (2012). Taphonomic analysis of rodent bone accumulations produced by Geoffroy's cat (Leopardus geoffroyi, Carnivora, Felidae) in Central Argentina. Journal of Archaeological Science 39, 1933-1941.

Montalvo, C. I., Tallade, P. O., Fernández, F. J., Moreira, G. J., Rafuse, D. J., \& De Santis, L. J. M. (2011). Bone damage patterns found in the avian prey remains of crested caracara Caracara plancus (Aves, Falconiformes). Journal of Archaeological Science 38, 3541-3548.

Muñoz, S. A., Mondini, M., Durán, V, \& Gasco, A. (2008). Los pumas (Puma concolor) como agentes tafonómicos. Análisis actualístico de un sitio de matanza en los Andes de Mendoza, Argentina. Geobios 41, 123-131.

Novaro, A. J., Funes, M. C., \& Walker, R. S. (2000). Ecological extinction of native preys of a carnivore assemblage in Argentine Patagonia. Biological Conservation 92, 2553.

Nowak, R. M. (1991). Walker's Mammals of the World, Vol. II. Baltimore: John Hopkins University Press.

Oliveira, T. G. (1994). Neotropical cats: ecology and conservation. São Luís: EDUFMA.

Oliver, J. S. (1993). Carcass processing by the Hadza: Bone breakage from butchery to consumption. En J. Hudson (Ed.), From bones to behavior (pp. 200-227). Illinois: Center for Archaeological Investigations.

Pardiñas, U. F. J. (1999). Tafonomía de microvertebrados en yacimientos arqueológicos de Patagonia. Arqueología 9, 265-308.

Pavao, B., \& Stahl, P. W. (1999). Structural Density assays of leporid skeletal elements with implications for taphonomic, actualistic and archaeological research. Journal of Archaeological Science 26, 53-66.

Perovic, P. \& Pereira, J. A. (2006). Felidae. En R. Bárquez, M. Díaz, \& R. Ojeda (Eds.), Mamíferos de la Argentina. Sistemática y distribución (pp. 93-100). Mendoza: Sociedad Argentina para el Estudio de los Mamíferos (SAREM).

Pickering, T. R., Heaton, J. L., Swodeski, S. E., \& Kuman, K. (2011). Taphonomy of bones from baboons killed and eaten by wild leopards in Mapungubwe National Park, South Africa. Journal of Taphonomy 9, 117-159.

Pobiner, B. (2008). Apples and oranges again: comment on "Conceptual premises in experimental design and their bearing on the use of analogy: an example from experiments on cut marks". World Archaeology 40, 466-479.

Prates, L., Prevosti, F. J., \& Berón, M. (2010). First records of prehispanic dogs in Southern South America (PampaPatagonia, Argentina). Current Anthropology 2, 273280.

Prevosti, F. J., Segura, V., Cassini, G., \& Martin, G. (2013). Revision of the systematic status of patagonian and pampean gray foxes (Canidae: Lycalopex griseus and L. gymnocercus) using 3D geometric morphometrics. Mastozoología Neotropical 20 (2), 289-300.

Quintana, C. A., Valverde, F., \& Mazzanti, D. L. (2002). Roedores y lagartos como emergentes de la diversificación de la subsistencia durante el Holoceno tardío en las sierras de la región pampeana, argentina. Latin American Antiquity 13 (4), 455-473.

Redford, K. H., \& Eisenberg, J. F. (1992). Mammals of the Neotropics, The Southern Cone. Vol. 2. Chile, Argentina, Uruguay, Paraguay. Chicago: University of Chicago Press.

Sala, N., Arsuaga, J. L., \& Haynes, G. (2013). Taphonomic comparison of bone modifications caused by wild and captive wolves (Canis lupus). Quaternary International. En prensa.

Saladié, P., Rodríguez-Hidalgo A., Díez, C., Martín-Rodríguez, P., \& Carbonell, E. (2013). Range of bone modifications by human chewing. Journal of Archaeological Science 40, 380-397.

Santiago, F. (2004). Los roedores en el "menú" de los habitantes de Cerro Aguará (provincia de Santa Fé): su análisis arqueofaunístico. Intersecciones en Antropología 5 , 3-18.

Selvaggio, M. M. (1994). Carnivore tooth marks and stone-tool butchery marks on scavenged bones: archaeological implications. Journal of Human Evolution 27, 215228.

Simonetti, J. A.; \& Cornejo, L. E. (1991). Archaeological evidence of rodent consumption in Central Chile. Latin American Antiquity 2 (1), 92-96.

Stoessel, L. (2012). Consumo de peces en el área ecotonal árida-semiárida del curso inferior del río Colorado (Provincia de Buenos Aires) durante el Holoceno tardío. Relaciones de la Sociedad Argentina de Antropología XXXVII, 159-182. 
Tivoli, A. M. (2012). ¿Intensificación? en el aprovechamiento de aves entre los cazadores-recolectores de la región del canal Beagle. Archaeofauna 21, 121-137.

Ximénez, A. (1975). Felis geoffroyi. Mammal Species 54, 1-4.

Zapata, S., Travaini, A., Delibes, M., \& Martínez-Peck, R. (2008). Identificación de morfogremios como aproximación al estudio de reparto de recursos en ensambles de carnívoros terrestres. Mastozoología Neotropical 15 (1), 85-101.
Zubimendi, M. A., Mazzitelli, L. C., Navarro, A. F., Zilio, L., \& Hammond, H. (2010). Primeras excavaciones en el sitio Palo Alto, Bahía Lángara, costa norte de Santa Cruz. En J. R. Bárcena, \& H. Chiavazza (Eds.), Arqueología Argentina en el Bicentenario de la Revolución de Mayo. XVII Congreso Nacional de Arqueología Argentina, Tomo V (pp. 2011-2016). Mendoza. 